\title{
Topography Mapping Patterns of Head and Neck Cancers, A Prospective and Cross-Sectional Study at Tertiary Care Centre at Nanded, India.
}

\author{
Balkrishna Harishchandrarao Namdhari ${ }^{1}$, Shubha Arvind Deshpande ${ }^{2}$ \\ I'Associate Professor, Pathology Department, Dr Shankarrao Chavan Government Medical College, Nanded, \\ under Maharashtra University of Health Sciences, Nashik, India) \\ ${ }_{2}^{2}$ (Professor and Head, Pathology Department, Dr Shankarrao Chavan Government Medical College, Nanded, \\ under Maharashtra University of Health Sciences, Nashik, India)
}

\begin{abstract}
International Classification of Diseases-Oncology 9(ICD-O) uses only a set of 4 characters for topography.Topography code remains same for all neoplasms of that site. Topography run from C00.0-C80.9.A decimal point (.) separates subdivisions of 3 character categories.

Mapping patterns of head and neck cancers of 18 months prospective study are conducted at tertiary care centre of state government run medical college and hospital at Nanded, Maharashtra, India. where 378 patients were selected out of that 60 patients have been diagnosed and confirmed histopathologically as cancers, these cases were plotted as per topographic codes and the leading topographic site was upper aero digestive tract, followed by thyroid cancers, this was also a follow up study, this similar study was done 7 years back in the same institute where the results were more or less same except the emergence of thyroid gland cancers. In present study in addition to thyroid cancers very few miscellaneous leading sites are added which are salivary gland cancers, skin +subcutaneous cancers and lymphatic cancers, so the group of topographic sub sites known as aerodigestive tract is seen in present study and is reduced to $66.67 \%$ while in previous study it was about 100\%.Presence of a group of topographic sub sites of aero digestive tract cancers is a common finding in all studies by using topography mapping.
\end{abstract}

Keywords: Cancer Registry, Follow up study, Head \&Neck Cancers, Mapping Pattern, Topography.

\section{Introduction}

To collect and classify the information on all cancer cases to create the statistics of the occurrence of cancer for providing a framework for assessment and control on impact of cancer in the community is called as cancer registry.

Microscopically verified percentage of cases is a quality indicator for oncology registries, and any variation in this percentage impacts on the possibility of cancer confirmation. Data came from pathology archives that guarantee the highest level of diagnostic accuracy for each case.

\section{Historical Background:}

Since 1893 there has been an international classification for coding mortality. In 1948 the International Statistical Classification of Diseases, Injuries and Cause of death (ICD) (9) is used to code, tabulate mortality and morbidity data. In 1976 the WHO published $1^{\text {st }}$ edition of ICD-O which had topography section based on malignant neoplasm rubric of ICD-9.In the 1990: $2^{\text {nd }}$ edition of ICD-O was developed by WHO used for cancer registries and pathology topographic codes from $\mathrm{C} 00$ to $\mathrm{C} 80.3^{\text {rd }}$ edition ICD-O was developed by working party convened by WHO. ICD-O Uses only set of 4 characters for topography .Topography code remains same for all neoplasms of that site.

Structure of Topography Code: Topography has 4 characters that run from C00.0 to C80.9. A decimal point (.) separates subdivisions of 3 character categories (Table 1).

\section{Objective}

Objective of this study is 'Topographic Mapping' of head and neck cancers in terms of leading sites.

\section{Material And Methods}

The present study was undertaken in the department of pathology, government medical college and hospital, a leading histopathology laboratory in the city. This is a prospective \& cross sectional study over the period of 18 months from January 2008 to June 2009. The selection of cases was done as follows,

1. The patients presented with superficially palpable head and neck lesion referred to cytology OPD.

2. Patient's admitted in hospital ward of our institute with clinical diagnosis of any head and neck neoplastic lesions. 
3. Patients attending cytological OPD in a private laboratory with head and neck lesion. Fine needle aspiration cytology (FNAC) smears in the cytology section of central clinical laboratory or in the respective ward in which the patient was admitted.

4. Microscopic verification done by biopsies and histopathological confirmation done on cytologically suspected cases for malignancies. These confirmed cases are included in this study.

Total of 385 aspirates from 378 cases were studied for the head and neck neoplastic lesions and mapping of head and neck cancers done (Table 2). All cases in this period were studied prospectively in the cytology section of the Department of Pathology, Government Medical College and Hospital with initial clinical evaluation, followed by fine needle aspiration cytology (FNAC) and subsequent histopathology wherever available.

Maximum number of aspirates from head and neck neoplastic lesions was found to be of lymph nodes $(56.37 \%)$ and minimum smears were from Odontogenic $(0.52 \%)$.

\section{Results}

Common primary site of head and neck malignancy was upper aero digestive tract $(66.67 \%)$ followed by thyroid $(11.66 \%)$ and lymph node malignancies $(5 \%)$ which were minimum (Table 3 ).

Lesions were studied of head and neck neoplastic lesions, histopathology in the available cases were done to reach the definitive diagnosis.

(Table 3) shows topographic mapping of histopathologically confirmed 60 malignant cases of head \& neck region shows the most common group of sub sites were found to be in the upper aero digestive tract $(66.67 \%)$.

\section{Discussion}

First all India report: 2001-2002 NCRP Bangalore (2004) of this institute [5], which is a report of cases the head and neck cancer cases whose \% relative proportion on topographic sites in males and females are as under shows leading sites under head and neck regions was upper aero digestive tract mostly $100 \%$ including tongue, larynx, hypo pharynx and mouth, the topographic acronyms are mentioned in (Table 4).

Hemant ahulawalia et al (2001) showed in their study series that upper aero digestive tract was the commonest site of head and neck neoplastic Lesions. Moreover histologically cases were of upper aerodigestive tract constituting $78.5 \%$.( Table 5)

Nandkumar et al (2005) data of 2, 17,174 microscopically diagnosed cancers in 2001-2002 from 68 districts across India shows topographic mapping of head and neck cancers as below

\section{Topographic site}

1. Upper aerodigestive tract including

Tongue

Mouth

Naso pharynx

2. Thyroid

\section{Code as per ICD10}

$\mathrm{C} 01-02$

$\mathrm{C} 03-06$

$\mathrm{C} 11 \quad$ and

$\mathrm{C} 73$
[7].

Present study of cancers of head and neck following are leading site of cancer

Topographic Site in the Head and Neck Region Relative Proportion \%

1. Upper aerodigestive tract

66.67

2. Thyroid

11.67

3. Skin+ Subcutaneous

08.33

4. Salivary glands

08.33

5. Lymph Nodes

05.00

[4].

Shows an addition of subcategory of thyroid, skin with subcutaneous area, salivary glands and lymph nodes, this added category includes major chunk of thyroid cancers $11.67 \%$ which was absent in previous study of same institute conducted 7 years back but this added category of cancers is also seen in national study of 68 districts across the India 2,17,174 microscopically diagnosed cancers studied, topographic leading site of cancer was thyroid cancer, this added category is seen in present study, ultimately mapping pattern has changed in 7 years. Prevalence of thyroid cancers is emerged that to $11.67 \%$ of total head and neck cancers as a leading site which is in addition to upper aero digestive tract. Studies by Hemant A. shows presence of upper aero digestive tract as a leading site only, this leading site is common in all studies which is compared in (Table 5). 
VI. Tables

Table 1.Structure of Topography Code Example of Breast Topographic site

C

$--\cdot$

C50.2

Breast, Upper Inner Quadrant

\begin{tabular}{|l|l|l|l|}
\hline \multicolumn{2}{|l|}{ Table 2. Topographic Sites and Aspirates Studied } \\
\hline Sr. No. & Sites & ASPIRATES & $\%$ \\
\hline 1 & Lymph node & $\mathbf{2 1 7}$ & $\mathbf{0 5 6 . 3 7}$ \\
\hline $\mathbf{2}$ & Salivary gland & $\mathbf{0 4 4}$ & $\mathbf{0 1 1 . 4 4}$ \\
\hline $\mathbf{3}$ & Thyroid & $\mathbf{0 4 2}$ & $\mathbf{0 1 0 . 9 0}$ \\
\hline $\mathbf{4}$ & Soft tissue & $\mathbf{0 5 7}$ & $\mathbf{0 1 4 . 8 0}$ \\
\hline $\mathbf{5}$ & Skin + Subcutaneous & $\mathbf{0 1 7}$ & $\mathbf{0 0 4 . 4 2}$ \\
\hline $\mathbf{6}$ & Nasal / PNS & $\mathbf{0 0 6}$ & $\mathbf{0 0 1 . 5 5}$ \\
\hline $\mathbf{7}$ & Odontogenic / bony & $\mathbf{0 0 2}$ & $\mathbf{0 0 0 . 5 2}$ \\
\hline $\mathbf{8}$ & Head and Neck Sites Studied & $\mathbf{3 8 5}$ & $\mathbf{1 0 0 . 0}$ \\
\hline
\end{tabular}

\begin{tabular}{|c|c|c|c|c|}
\hline Sr. No. & Primary Site & $\begin{array}{l}\text { Topographic } \\
\text { Coding }\end{array}$ & $\begin{array}{l}\text { No. of } \\
\text { Malignant Cases }\end{array}$ & $\%$ \\
\hline 1 & Upper aerodigestive tract & $\begin{array}{l}\text { C04.0-C06.9 } \\
\text { C01.9-C02.9 } \\
\text { C10.0-C11.9 } \\
\text { C13.0-C14.8 }\end{array}$ & 40 & 066.67 \\
\hline 2 & Thyroid & C73.9 & 07 & 011.67 \\
\hline 3 & Skin + Subcutaneous & C44.0-C44.0 & 05 & $\mathbf{0 0 8 . 3 3}$ \\
\hline 4 & Salivary gland & C07.9-C08.9 & 05 & $\mathbf{0 0 8 . 3 3}$ \\
\hline 5 & Lymph nodes & C77.0 & 03 & 005.00 \\
\hline Total & Patients Studied & & $\begin{array}{l}60 \text { Cancer } \\
\text { Cases of } \\
\text { Head and Neck. }\end{array}$ & 100.00 \\
\hline
\end{tabular}

\begin{tabular}{|c|c|c|c|c|c|}
\hline \multirow{2}{*}{\multicolumn{3}{|c|}{$\begin{array}{l}\text { Table 4. First All India Report } 2 \\
\text { Showing Topographic site Gender wi } \\
\text { Grouping for Determining Leading } \\
\text { Head \& Neck [5]. } \\
\text { Males }\end{array}$}} & \multicolumn{3}{|c|}{$\begin{array}{l}\text { 01-2002 of NCRP of this Institut } \\
\text { se with ICD-O Coding with Mode } \\
\text { Sites of Cancer in the Region }\end{array}$} \\
\hline & & & \multirow{3}{*}{ Sr No } & Females & \\
\hline \multirow[t]{2}{*}{ Sr No } & $\begin{array}{l}\text { Topographic } \\
\text { Acronym }\end{array}$ & Codes & & $\begin{array}{l}\text { Topographic } \\
\text { acronym }\end{array}$ & Codes \\
\hline & \multicolumn{2}{|c|}{ Upper aero digestive tract } & & \multicolumn{2}{|c|}{ Upper aero digestive tract } \\
\hline 1 & Tongue & $\mathrm{C} 01 \mathrm{C} 02$ & 1 & Tongue & $\mathrm{C} 01 \mathrm{C} 02$ \\
\hline 2 & Larynx & $\mathrm{C} 32$ & 2 & Mouth & $\mathrm{C} 04 \mathrm{C06}$ \\
\hline 3 & Hypo pharynx & C13 & 3 & Larynx & $\mathrm{C} 32$ \\
\hline \multicolumn{3}{|c|}{ Malignant Neoplasm of Topographic site } & \multicolumn{3}{|c|}{ Malignant Neoplasm of Topographic site } \\
\hline
\end{tabular}

Abbreviations of topographic codes

C01 Malignant neoplasm of base of tongue

C02 Malignant neoplasm of other and unspecified parts of tongue 
C04 Malignant neoplasm of mouth

C06 Malignant neoplasm of other and unspecified parts of mouth

C07 Malignant neoplasm of parotid gland

C08 Malignant neoplasm of other and unspecified major salivary glands

C10 Malignant neoplasm of oropharynx

C11 Malignant neoplasm of naso pharynx

C13 Malignant neoplasm of hypo pharynx

C14 Malignant neoplasm of other and ill-defined sites in the lip, oral cavity and pharynx.

C32 Malignant neoplasm of larynx

C44 Malignant neoplasm of other malignant neoplasm of skin

C73 Malignant neoplasm of thyroid gland.

[3].

\begin{tabular}{|c|c|c|c|}
\hline Study workers (Year) & Type of study & Commonest site & $\%$ \\
\hline $\begin{array}{l}\text { Hemant Ahulawalia et al } \\
\text { (2001) }\end{array}$ & Prevalence study & $\begin{array}{l}\text { Upper aerodigestive tract (including } \\
\text { Oral Cancer+ Larynx Oropharynx) }\end{array}$ & 078.50 \\
\hline $\begin{array}{l}\text { A. Nandakumar } \\
\text { SB Rathod, } \\
\text { Deshpande \&A } \\
\text { Namdhari } \\
\\
(2004)\end{array}$ & $\begin{array}{l}\text { Prevalence study of Topographic } \\
\text { sites }\end{array}$ & $\begin{array}{l}\text { Upper aero digestive tract } \\
\text { (including Tongue+ Larynx }+ \text { Hypo } \\
\text { pharynx+ Mouth) }\end{array}$ & 100.00 \\
\hline $\begin{array}{l}\text { Nandkumar et al } \\
(2005) \\
\end{array}$ & $\begin{array}{l}\text { All India Data of } \\
\text { Prevalence study of Topographic } \\
\text { sites }\end{array}$ & $\begin{array}{l}\text { Upper aero digestive tract } \\
\text { (including Tongue+Mouth+Naso } \\
\text { pharynx)Thyroid. }\end{array}$ & $\begin{array}{l}\text { Leadin } \\
\text { g sites }\end{array}$ \\
\hline $\begin{array}{l}\text { Present Study } \\
(2008+2009)\end{array}$ & $\begin{array}{l}\text { Prevalence study of topographic } \\
\text { sites }\end{array}$ & $\begin{array}{l}\text { 1. Upper aerodigestive tract } \\
\text { (Including Tongue +hypo pharynx } \\
+ \text { larynx+ mouth) } \\
\text { 2. Thyroid } \\
\text { 3. Skin + Subcutaneous } \\
\text { 4. Salivary glands } \\
\text { 5. Lymph Node }\end{array}$ & $\begin{array}{c}66.67 \\
\\
11.67 \\
08.33 \\
08.33 \\
05.00 \\
\end{array}$ \\
\hline
\end{tabular}

\section{Conclusion}

Mapping patterns of head and neck cancers of 18 months prospective and cross sectional study 60 patients have been diagnosed and confirmed histopathologically as cancers, these cases were plotted as per topographic codes and the leading topographic site was upper aero digestive tract, followed by thyroid cancers, in addition to thyroid cancers few miscellaneous leading sites are added which are salivary glands cancers, skin +subcutaneous cancers and lymphatic cancers, so aerodigestive tract in present study (Table 5) reduced to $66.67 \%$ [4], while in previous study it was about $100 \%$. Aero digestive tract cancers are common in all studies by using topography mapping.

\section{Acknowledgements}

I sincerely express thanks to my post graduate student Dr.Amit U. Maniyar for creating the data base for this study.

\section{References}

[1]. Kishore Chaudhry \& Usha k. Luthra, Cancer registration in India 50 years of cancer control in India.

[2]. Adele Calderella, Emanuel Crocetti, Gian luigi Taddei, Eugenio Paci. Cytopathological diagnosis in a cancer registry, a useful diagnostic tool? Cancer (cancer cytopathology) April 2007; vol. 111;2

[3]. April Fritz, Constance Percy, Andrew Jack, Kanagaratnam, Shanmugaratnam, Leslie Sobin D Max Parkin, Sharon Whelan, ICD-O International classification of disease for oncology, $3^{\text {rd }}$ edition WHO Geneva2000.

[4]. Amit U. Maniyar, Study of cytodiagnosis of head and neck neoplastic lesions and mapping patterns of head and neck

[5]. cancers, MD Pathology diss., Dr Shankarrao Chavan Government Medical College, Nanded India ,Maharashtra University of Health Sciences,Nashik,India,2010.

[6]. A. Nandakumar. Development of an atlas of cancer in India, A project of the national cancer registry programme (Indian council of medical research) supported by WHO: First all India report : 2001-2002 Mapping patterns of cancer, Information technology in medicine-Measuring burden of disease,7.63 Government Medical College ,Nanded(Centre code:0037),Volume II,402-403,National Cancer Registry Programme(ICMR),Bangalore,India .April 2000

[6]. Hemant Ahulawalia, SC Gupta, Mangal Singh, Vatsla Mishra, et al Spectrum of head and neck cancers at Allahabad, Indian journal of Otolaryngology and head and neck surgery vol. 53 no. 1, January - march2001.

[7]. Nandkumar et al Geographic pathology revisited: Development of an atlas of cancer in India, Int. J. Cancer: 116,740-754(2005). 